HISPANIA NOVA

Revista de Historia Contemporánea

Núm. 15, año 2017

ISSN: 1138-7319 - Depósito legal: M-9472-1998 http://www.uc3m.es/hispanianova

\title{
ARTíCULOS
}

\section{RELACIONES PERSONALES Y DE PODER EN LOS CENTROS LIBERTARIOS MADRILEÑOS: EL CASO DEL ATENEO LIBERTARIO DE VENTAS (VERANO-OTOÑO DE 1936)}

\author{
Soraya Gahete Muñoz \\ Fernando Jiménez Herrera \\ Universidad Complutense de Madrid \\ sgahete@ucm.es \\ feriimenezherrera@gmail.com
}

\author{
Personal relationship and the power in \\ the libertarian center from Madrid: the \\ case of the Libertarian Ateneo of Ventas \\ (summer-autumn, 1936)
}

Recibido: 08/02/2016 - Aceptado: 30/09/2016

\begin{abstract}
Cómo citar este artículo/Citation:
Soraya GAHETE MUÑOZ y Fernado JIMÉNEZ HERRERA (2017), "Relaciones personales y de poder en los centros libertarios madrileños: el caso del Ateneo Libertario de Ventas (veranootoño de 1936)", Hispania Nova, 15, págs. 100 a 124,

DOI: https://doi.org/10.20318/hn.2017.3482
\end{abstract}

Copyright: (c) HISPANIA NOVA es una revista debidamente registrada, con ISSN 1138-7319 y Depósito Legal M 9472-1998. Los textos publicados en esta revista están -si no se indica lo contrario- bajo una licencia Reconocimiento-Sin obras derivadas 3.0 España de Creative Commons. Puede copiarlos, distribuirlos y comunicarlos públicamente siempre que cite su autor y la revista y la institución que los publica y no haga con ellos obras derivadas. La licencia completa se puede consultar en: http://creativecommons.org/licenses/by-nd/3.0/es/deed.es
Resumen: La Guerra Civil española generó una serie de dinámicas que modificaron las relaciones de género, siendo más notorias éstas en la retaguardia republicana. En el Madrid de la Guerra Civil, la mayor parte de los centros obreros adquirieron una serie de nuevas atribuciones que les consolidaron como una alternativa al modelo republicano burgués. Uno de estos centros fue el Ateneo Libertario de Ventas, donde se desempeñaron funciones culturales, heredadas del periodo republicano, y otras nuevas fruto de las necesidades de la guerra, tales como: la función defensiva y la humanitaria. Este trabajo tiene como objeto estudiar no solo el funcionamiento interno de este centro, sino también analizar las relaciones de género e interpersonales dentro del mismo.

Palabras clave: Guerra Civil, relaciones de género, anarquismo, ateneos, Madrid.
Abstract: The Spanish Civil War produced changes which modified gender relationships, especially in the Republican rear. During the Civil War the majority of working centre gained new responsibilities which transformed it into an alternative bourgeois republican model. One of these centres was The Libertarian Ateneo of Ventas, where roles such as cultural matters, which were inherited during the Republican period, were carried out alongside others new activities during the civil war: defensive and humanitarian. The purpose of this work is not only to study the internal system of this centre, but to study gender and interpersonal relationships in The Libertarian Ateneo of Ventas.

Key Words: Civil War, gender relationships, anarchism, ateneos, Madrid. 


\section{RELACIONES PERSONALES Y DE PODER EN LOS CENTROS LIBERTARIOS MADRILEÑOS: EL CASO DEL ATENEO LIBERTARIO DE VENTAS (VERANO-OTOÑO DE 1936)}

\section{INTRODUCCIÓN}

Estábamos en un grupo denominado Sol y Vida, con chicos y chicas. Montábamos obras de teatro, hacíamos gimnasia, íbamos de excursión a la montaña y al mar... Era un grupo cultural y recreativo a la vez... Siempre había después una especie de charla. De ese modo, se despertaba nuestra curiosidad por nuevas ideas y se creaba un sentimiento de compañerismo. Es verdad que íbamos también a las conferencias del sindicato, o de otras por el estilo, pero las relaciones dentro de nuestro grupo eran más estrechas, las explicaciones más completas. $Y$ ahí es donde nos formamos, ideológicamente y en profundidad $^{1}$.

Los ateneos libertarios aparecieron en España durante la II República con la finalidad de ser centros difusores de las ideas anarquistas y de nuevos modelos sociales. La función más destacada de estos centros fue la educativa, creando escuelas de primera enseñanza, impartiendo clases nocturnas para adultos o generando espacios de debate y discusión. La peculiaridad del sistema pedagógico anarquista se basó en el modelo de escuela racionalista. No obstante, se imprimió un componente ideológico sobre todas estas actividades. La vida de estos centros estuvo regida por un reglamento que todos sus socios tuvieron que cumplir. En el plano teórico, las relaciones entre sus miembros estuvieron caracterizadas por una idea de comunidad basada en la propia individualidad, donde no había comunidad sin individuos e individuos sin comunidad. La igualdad y la libertad fueron los principales conceptos que deberían formar parte de la esencia del individuo; conceptos que según la teoría anarquista serían aprendidos a través de la práctica, "las personas aprenden a ser libres solo ejercitándose en libertad" ${ }^{2}$. Pero, ¿cómo se materializaron esas ideas de comunidad basadas en la libertad e igualdad entre sus miembros?

Un estudio más profundo de los ateneos libertarios permitirá centrarse en una serie de aspectos que en investigaciones de carácter macro quedan desatendidas, tales como: las relaciones interpersonales de los miembros que componían estos comités, la relación de los centros con su entorno, las labores humanitarias y culturales, etc. En este trabajo recurrimos al término contemporáneo "comité" para hacer referencia a todos aquellos centros que durante la Guerra Civil y la

\footnotetext{
1 Entrevista a Enriqueta Rovira, 28 de diciembre de 1981, Castellnaudary (Francia). Recogido en Martha ACKELSBERG: Mujeres Libres. El anarquismo y la lucha por la emancipación de las mujeres, Barcelona, Virus, 2006, p. 67.

2 Isaac PUENTE: El comunismo libertario. Sus posibilidades de realización en España. Valencia, Biblioteca de Estudios, 1933, p. 15. Recogido ibídem, p. 68.
} 
posguerra fueron conocidos con el nombre de "cheka", entre ellos los ateneos libertarios. Este nombre hace referencia a la policía política rusa durante los primeros años de la revolución bolchevique y fue utilizada deliberadamente por los aparatos propagandísticos de los sublevados para relacionar la revolución social acontecida en España, tras el golpe del 18 de julio de 1936, con este régimen ${ }^{3}$. Hasta ahora, los trabajos más destacados que habían analizado los comités españoles se han centrado en el estudio de la represión en la zona republicana, apenas prestando atención a los temas mencionados anteriormente ${ }^{4}$.

El objetivo principal de este trabajo es abordar las relaciones interpersonales en el Ateneo Libertario de Ventas desde una perspectiva de género ${ }^{5}$. Este tema no ha sido abordado para ningún comité y es sumamente importante conocer qué tipo de relaciones se gestaron en estos centros y cómo se conjugan con la ideología dominante en los mismos. También es fundamental analizar estas relaciones interpersonales desde el punto de vista de las relaciones de género, ya que en un momento como fue la Guerra Civil los parámetros que determinaban los roles de género fueron modificados. A través de este trabajo se verá el grado y el alcance de transformación de los papeles asignados a mujeres y hombres durante el conflicto.

La elección del Ateneo Libertario de Ventas responde, por un lado, al interés de analizar las relaciones de género en un centro de pensamiento anarquista, en principio más tendente, por ideología, a aceptar unas relaciones de igualdad entre sus miembros. Por otro lado, la elección de Ventas, ejemplo de barrio obrero, se debió a que en dicho barrio existieron estructuras culturales, políticas y sindicales anteriores a la guerra; es decir, una larga tradición de movilización obrera. También, la elección del Ateneo de Ventas como objeto de estudio se debió a la existencia de un mayor volumen documental.

Para poder conocer el funcionamiento interno de este centro y las relaciones entre sus miembros se ha recurrido a un tipo de fuente de carácter judicial como son los Consejos de Guerra franquistas, realizados al finalizar la Guerra Civil española. Para ello, en primer lugar, se procedió a la consulta de la Causa General, actualmente en el Centro Documental de la Memoria Histórica en Salamanca y accesible a través de la página web PARES $^{6}$. El resultado de esta primera búsqueda

3 Para más información sobre este aspecto, ver: Fernando JIMÉNEZ HERRERA: "El Comité Provincial de Investigación Pública a través de la documentación custodiada en el Archivo Histórico Militar de Madrid", Hispania Nova, Revista de Historia Contemporánea, no 12, 2014, pp. 6-7.

${ }^{4}$ Los estudios más relevantes, para el caso de Madrid, sobre la represión en zona republicana o que tratan este tema en sus obras son: Javier CERVERA GIL: Madrid en Guerra. La ciudad clandestina, 1936-1939, Madrid, Alianza Editorial, 2006. Paul PRESTON: El Holocausto Español. Odio y exterminio en la Guerra Civil y después, Barcelona, Debate, 2011. Julius RUIZ: El Terror Rojo. Madrid 1936, Madrid, Espasa, 2012. No obstante, hay obras que se han dedicado al estudio pormenorizado de este tipo de centros en otras zonas, como Agustín GUILLAMÓN IBORRA: La Revolución de los Comités. Hambre y violencia en la Barcelona Revolucionaria. De junio a diciembre de 1936, Barcelona, Aldarull y El Grillo Libertario, 2012. Josep Antoni POZO GONZÁLEZ: Poder legal y Poder Real en la Cataluña Revolucionaria de 1936, Barcelona, Espuela de Plata, 2012.

${ }^{5}$ Este trabajo es fruto de una ponencia presentada en el Seminario América Latina y España. Bajo las sombras dictatoriales del siglo XX, celebrado el 15 de septiembre de 2015 y dirigido por el profesor Jorge Marco Carretero. La ponencia llevaba por título El Ateneo Libertario de Ventas durante el verano-otoño de 1936.

${ }^{6}$ http.www.pares.mcu.es 
permitió conocer las personas que fueron juzgadas por su pertenencia al Ateneo Libertario de Ventas. Una vez conocidos sus nombres y apellidos, en segundo lugar, se procedió a su búsqueda en el Archivo General Histórico de Defensa, situado en el Paseo de Moret (Madrid). Allí accedimos a cada uno de los expedientes personales de las personas inculpadas, si bien, no todos ellos pudieron ser consultados, ya que 19 de un total de 137, se encuentran en mal estado. En algunos casos, las personas inculpadas contaban con dos expedientes, pero no siempre se encontraba información sobre el acusado o acusada, al ser los expedientes, en la mayoría de los casos, causas colectivas.

La información que se ha obtenido de estos expedientes es variada, siendo algunos muy ricos en detalles y otros bastante escasos de contenido. Se ha tenido muy en cuenta el tipo de documentación consultada, ya que es una fuente con un claro objetivo incriminatorio hacia las personas inculpadas, por lo que se ha realizado una importante crítica de fuentes ${ }^{7}$.

Dentro de los expedientes consultados habría que destacar de forma especial los expedientes personales de las mujeres. En ellos, la información sobre su actuación durante la guerra es mucho menor y las acusaciones contra ellas, aspecto que se desarrollará más adelante, resultan particularmente significativas en cuanto que no se las acusa de asesinatos directos, salvo una excepción, sino de ser instigadoras de los mismos. Sin embargo, las condenas son significativamente más elevadas para ellas que para aquellos hombres acusados también de "auxilio a la rebelión" ${ }^{8}$.

\section{Contextualización}

La sociedad española de los años treinta había experimentado cambios importantes, en lo que a las relaciones de género se refiere, consecuencia de la pequeña modernización emprendida durante la Dictadura primorriverista, y que continuó con más fuerza durante los años en los que el régimen republicano estuvo gobernando. Las influencias exteriores fueron también muy importantes con la llegada de un nuevo modelo de mujer, la mujer moderna, que en España fue seguido por un grupo no muy numeroso de la sociedad femenina; ya que seguía pesando más el modelo de "ángel del hogar", del siglo XIX.

El "problema femenino", como muchas veces se ha denominado, a lo que las mujeres representan o deben representar en las sociedades, es un debate con siglos de historia. Sin embargo, en el siglo XIX diferentes corrientes de pensamiento auspiciadas por la fuerza y el prestigio con que la medicina entró en aquel momento en los debates intelectuales, dieron una visión de lo que "la

\footnotetext{
${ }^{7}$ José Luis LEDESMA VERA: Los días de llamas de la revolución. Violencia y política en la retaguardia republicana de Zaragoza durante la Guerra Civil, Zaragoza, Institución Fernando el Católico, 2003, pp. 31-32.

${ }^{8}$ Las penas franquistas dependen de la gravedad de los delitos cometidos, aunque prima una gran arbitrariedad a la hora de la imposición de las mismas. Lo que sí aseguraba el sistema era la total indefensión de los acusados y acusadas. Guzmaro GÓMEZ BRAVO: "El desarrollo penitenciario en el primer franquismo (1939-1945)", Hispania Nova, no 6, año 2006, p. 19. Las penas serían "Adhesión a la Rebelión", "Auxilio a la Rebelión", "Inducción a la Rebelión" y "Apología de la Rebelión". Según la acusación se podía condenar desde la pena de muerte hasta los 6 años y 1 día de "reclusión menor". Con esta terminología, el régimen franquista no solo condenó a millares de personas, sino que invirtió los términos de la guerra, haciendo ver que el Gobierno legítimo de la II República era el rebelde y los sublevados, los representantes de la legalidad. Todo ello, como forma de legitimación de un régimen ilegal que nació de un golpe de estado.
} 
naturaleza femenina" representaba, totalmente negativa, además de muy domesticada. Durante el siglo XIX el movimiento feminista experimentó un gran auge a través, fundamentalmente, del movimiento sufragista y que resultó fundamental para el despertar de una conciencia feminista en muchas mujeres. En España, la influencia de este movimiento no tuvo una excesiva repercusión. Algunas autoras, como Geraldine Scanlon ${ }^{9}$, sostienen la idea de que ni siquiera hubo feminismo en España en aquella época. El debate sobre lo "femenino" y el papel de las mujeres en la sociedad fueron introducidos por teorías de pensamiento auspiciadas por Gregorio Marañón, González Revilla, César Juarros, etc. Debates en los que la presencia femenina se fue haciendo más presente con figuras como Carmen de Burgos, Carmen Moreno y Díaz Prieto, Margarita Nelken, etc., si bien con unas concepciones de la mujer y de lo femenino, muy ligadas a la función maternal ${ }^{10}$.

En España el movimiento anarquista se interesó por "la problemática de la mujer", desarrollándose diferentes tendencias. Por un lado, hubo una línea muy influida por el pensamiento de Proudhon, para quien, la función de la mujer se limitaba a la reproducción. De esta forma, dicho pensamiento iba en la línea de lo argumentado por muchos otros pensadores donde la biología, considerada como una ciencia determinista, era la que determinaba las funciones que mujeres y hombres debían desempeñar en la sociedad. Por otro lado, existió otra visión, procedente del pensamiento de Bakunin, que abogaba en la teoría por la completa igualdad de la mujer y del hombre. Según la historiadora Mary Nash, esta concepción "era la más extendida, al menos a nivel teórico, entre los anarquista" ${ }^{11}$. De hecho, esta línea de pensamiento fue la adoptada en el Congreso anarquista de Zaragoza de mayo de 1936.

La organización femenina anarquista más destacada fue Mujeres Libres, fundada en abril de 1936. Mujeres Libres, que publicaría una revista con el mismo nombre, tuvo como objetivo inicial "la emancipación de la mujer y su captación para el movimiento libertario"12. Según esta organización era fundamental, liberar a las mujeres obreras de su triple esclavitud: esclavitud de ignorancia, esclavitud como productora y esclavitud como mujer. Mujeres Libres tuvo sus discrepancias con la Confederación Nacional de Trabajadores (CNT), la Federación Anarquista Ibérica (FAI) y la Federación Ibérica de Juventudes Libertarias, ya que en estas organizaciones se seguía manteniendo una serie de prejuicios contra las mujeres, y se negaron a que esta organización pudiese tener cuotas de autonomía, tal y como pedían las integrantes de Mujeres Libres.

Esta lucha de Mujeres Libres con el resto de organizaciones anarquistas es un ejemplo de las dificultades que encontraron las mujeres para liberarse del yugo masculino, incluso en aquellas que abogaban por la libertad. El planteamiento de Mujeres Libres estuvo basado en la idea de que las mujeres debían llevar a cabo una doble lucha. Por un lado, una lucha como obreras que liberara a los obreros de la situación de explotación en la que se encontraban. Pero, por otro lado, una lucha como mujeres por conseguir su liberación, ya que fueron conscientes de que la desaparición de la sociedad de clases no iba a acabar con su categoría de sujetos subordinados.

\footnotetext{
${ }^{9}$ Geraldine SCANLON: La polémica feminista en la España contemporánea, México, Siglo veintiuno, 1976.

${ }^{10}$ Nerea ARESTI: Médicos, Donjuanes y Mujeres Modernas, Gipuzkoa, Universidad del País Vasco, 2001.

${ }^{11}$ Mary NASH: Mujeres Libres. España, 1936-1939, Barcelona, Tusquets, 1975, pp. 10-11.

12 ibídem, p. 15.
} 
El hombre revolucionario que hoy lucha por su libertad, solo, combate contra el mundo exterior. Contra un mundo que se opone a sus anhelos de libertad, igualdad y justicia social. La mujer revolucionaria, en cambio, ha de luchar en dos terrenos: primero por su libertad exterior, en cuya lucha tiene al hombre de aliado por los mismos ideales, por idéntica causa; pero, además, la mujer ha de luchar por la propia libertad interior, de la que el hombre disfruta ya desde hace siglos. Y en esta lucha, la mujer está sola ${ }^{13}$.

Frente a otras organizaciones de mujeres ligadas al Partido Comunista o al Partido Socialista, las mujeres anarquistas fueron conscientes desde un primer momento de su doble esclavitud, como trabajadoras y como mujeres. A pesar del pensamiento más igualitario que predominaba entre los anarquistas, las mujeres dentro de este ámbito tuvieron dificultades y se encontraron con numerosos obstáculos a la hora de poner en práctica esa "igualdad". Entre los militantes anarquistas predominó, en general, una concepción de la mujer muy ligada a la defendida desde los ámbitos conservadores. Para estos sectores el papel principal de las mujeres se encontraba en el hogar, y su contribución a la sociedad se realizaba a través de la reproducción.

Otro aspecto a tener en cuenta, por influyente en el objeto de estudio, es el de Madrid de la Guerra Civil en el año 1936. El día 17 de julio de 1936 las tropas africanistas se sublevan en el protectorado marroquí. Los rumores sobre el golpe se extendieron rápidamente entre la ciudadanía de la Península, y pronto se unieron a ella algunas guarniciones militares. El objetivo principal de los sublevados fue tomar Madrid, sin embargo, el golpe fracasó en la capital, y la ciudad se mantuvo fiel a la República. La intención de los sublevados en Madrid fue la de motivar la sublevación en los cuarteles periféricos y converger en el centro de la capital. No obstante, ante el desbordamiento popular pidiendo armas, optaron por el acuartelamiento. El efecto de la sublevación en la zona Gubernamental fue el debilitamiento del poder político, favoreciendo este acontecimiento, a que otro tipo de poderes, como fueron los partidos, los sindicatos y otras organizaciones sociales, llegaran a imponerse casi con total impunidad. Esta situación se dejó sentir con gran intensidad en ciudades como Madrid y Barcelona.

Esta situación inesperada de pérdida de atribuciones por parte del Estado republicano, abrió la puerta a una serie de actores políticos y sindicales para ocupar posiciones de poder y competir directamente con el Estado por el monopolio del control de la retaguardia; es decir, el golpe de estado que defendía luchar contra una revolución social, inexistente en España antes del 18 de julio de 1936, produjo una revolución social en la zona Gubernamental ${ }^{14}$. Una revolución social no preparada, sino improvisada, según iban sucediendo los acontecimientos. De esta forma, órganos tradicionales como: los ateneos libertarios (para el caso anarquista), las agrupaciones y círculos (para los socialistas) o las radios (para los comunistas), adquirieron nuevas funciones, y pasaron a ser centros reales de poder en las zonas donde estaban instalados. Fueron organismos de administración de las barriadas, ya que atendían labores humanitarias como: el reparto de alimentos o ropas, fruto de las incautaciones; labores defensivas con controles y patrullas de milicianos y milicianas; labores de justicia a través de unos tribunales particulares. También se encargaron de localizar a todas aquellas personas sospechosas de posibles apoyos a los sublevados, investigándolos a través de registros, juzgándolos y sentenciándolos. Ante esta situación, los simpatizantes de la sublevación tenían dos salidas: o bien

\footnotetext{
13 "Mujeres Libres", VIII mes de la Revolución, en: ibídem, p. 131.

14 Julio ARÓSTEGUI: Por qué el 18 de julio..., op. cit., p. 323.
} 
intentar cruzar la "frontera" y poder pasar a la zona sublevada, o bien quedarse e intentar sobrevivir. Algunas personas partidarias de la sublevación no dudaron en recurrir a las armas como forma de resistencia ante la victoria republicana en Madrid, fueron los llamados pacos y coches fantasma ${ }^{15}$.

Las labores represivas y coercitivas que incorporaron estos centros tuvieron una limitación temporal. A lo largo de la contienda, el Gobierno de la República intentó recuperar el monopolio perdido en este tipo de atribuciones y para ello llevo a cabo una serie de iniciativas: descalificar a través de la prensa a estos colectivos con términos como el de "incontrolados", creación del Comité Provincial de Investigación Publica, las Milicias de Vigilancia de Retaguardia, los Tribunales Populares y toda una serie de normativas y leyes sobre circulación de vehículos, posesión de armamento o personal autorizado para efectuar detenciones. Aun así, estas normativas no tuvieron un efecto visible en el Madrid de la guerra hasta la llegada al gobierno de Largo Caballero y la formación de la Junta Delegada de Defensa de Madrid. En el caso madrileño, las funciones coercitivas y represivas protagonizadas por estos centros se prolongaron más que en otras ciudades debido a los efectos de la guerra sobre la ciudad y su población, al ser frente de guerra desde noviembre de 1936. Se pueden dar por concluidas este tipo de funciones ejercidas por estos centros a partir de enero de 1937, lo que no quiere decir que desapareciesen como entidades físicas (comités) o que abandonasen otras funciones, como las culturales o las educativas.

Los antiguos órganos representativos del orden republicano, considerados como burgueses, como los ayuntamientos, tuvieron que competir con estos nuevos organismos para poder recuperar su hegemonía en las diferentes barriadas. No obstante, sufrieron una serie de cambios relevantes, y en muchos casos, presionados por estos nuevos poderes, tuvieron que ampliar sus funciones y equipararse a estos centros para poder competir con ellos y poder volver a ser el órgano representativo de la población y del poder hegemónico del Estado. Otra de las formas de control de las barriadas fue la formación de Comités; centros donde se representaron a todas las fuerzas que lucharon con la República. En numerosas ocasiones el presidente de estos comités fue el alcalde de la zona, instalándose incluso en el propio ayuntamiento. Un símbolo de la nueva situación generada a raíz del golpe de estado.

Sin embargo, como se ha comentado anteriormente, el poder de estos centros irá disminuyendo a lo largo de la guerra. Sobre todo tras la formación del gobierno de Largo Caballero y su gabinete, compuesto por todos los partidos y sindicatos defensores de la República excepto el Partido Obrero de Unificación Marxista (POUM), el Partido Sindicalista de Ángel Pestaña, y en un principio, la CNT y la FAI (entraron a formar parte del gabinete de gobierno el 5 de noviembre de 1936, un gobierno de Unidad Antifascista) ${ }^{16}$. También, esta recuperación de poder se debió a la estabilización de los frentes de guerra, con excepción de la ciudad de Madrid, ya que fue el centro del conflicto hasta abril de $1937^{17}$.

\footnotetext{
15 Julius RUIZ: El Terror..., op. cit., pp. 94-95.

${ }^{16}$ Julio ARÓSTEGUI: Largo Caballero. El tesón y la quimera, Barcelona, Debate, 2013, pp. 474-475.

${ }^{17}$ José Luis LEDESMA VERA: Los días de..., op.cit., pp. 305-309.
} 
En lo que respecta al anarquismo, como corriente de pensamiento, se extendió por España durante la segunda mitad del siglo XIX. El anarquismo supuso una forma de pensamiento y de concebir la realidad de una forma diferente a la expuesta por el capitalismo. Las zonas donde tuvo una mayor presencia este movimiento fue en Andalucía y, posteriormente, en Barcelona. Dentro del anarquismo hubo diversas organizaciones aunque la que tuvo una mayor presencia fue la Confederación Nacional de Trabajadores, CNT, creada en 1910. La otra gran organización anarquista fue la Federación Anarquista Ibérica, FAI, creada en 1927. Su principal competidor para captar afiliados fue la Unión General de Trabajadores, UGT, socialista, ligada al Partido Socialista Obrero Español, PSOE $^{18}$.

Fue durante la II República donde el movimiento anarquista adquirió mayor relevancia, en cuanto a filiación se refiere ${ }^{19}$. Los cambios que prometía el nuevo régimen produjeron el apoyo entusiasta de los anarquistas. No obstante, ante los sucesivos encontronazos entre las autoridades y los anarquistas unido a las huelgas, pronto se deterioró esta confianza, y el entusiasmo se fue tornando en un fuerte deseo de cambio. Sin embargo, estas tensiones también se produjeron dentro del movimiento, dando lugar a diversas alternativas, como fue el caso del Partido Sindicalista.

En esta revitalización y salida de la clandestinidad que supone la proclamación de la II República aparecieron los ateneos libertarios. Con anterioridad existían otros centros culturales, pero éstos estaban controlados por las élites y muchas veces orientados a esas élites o al ocio, más que a la difusión de unos ideales o a fomentar la cultura entre las clases más humildes. Los ateneos libertarios fueron centros que se crearon en las barriadas durante la II República y su función fundamental era la difusión de la cultura revolucionaria, diferente a la que se daba en las instituciones estatales, sobre todo a través del llamado "método racionalista". No obstante, también fueron centros de difusión del ideal anarquista y de propaganda. Estos centros se mantuvieron a través de las cuotas de los socios. En el caso de que los ateneos acabaran siendo inviables, todo lo que éstos tenían lo donaban a otros que continuaban, sobre todo los libros. Entre los que se crearon antes de la guerra está el de Ventas en 1933. Se constituyó al contar con el respaldo de la barriada y otros centros anarquistas, como reflejaron en el periódico $C N T$, en el cual solicitaban ayuda para la creación de una biblioteca mediante el envío de libros, prensa, folletos o donativos. Todo ateneo contaba con un reglamento interno propio o carnets para sus socios y tenían como espacios un salón cultural o una biblioteca, donde se organizaban las clases, charlas, lecturas comentadas. En el caso del Ateneo de Ventas su reglamento fue aprobado por la DGS en noviembre de 1933, hasta ese momento realizó diversas actividades en otras sedes anarquistas como el domicilio social de los ferroviarios en la calle Fuencarral, $43^{20}$.

En cuanto a la organización de estos centros culturales destaca la Junta Directiva, compuesta por el bibliotecario, el presidente, el secretario, el tesorero y dos vocales. Todos estos fueron los cargos

\footnotetext{
18 Julián CASANOVA (Coordinador), Tierra y Libertad. Cien años de anarquismo en España, Barcelona, Editorial Crítica, 2010.

${ }^{19}$ Como muestra de este fortalecimiento del movimiento anarquista durante la República: la CNT en otoño de 1931 estuvo compuesta por 800.000 afiliados y "Mujeres Libres", 20.000 afiliadas hasta el inicio de la Guerra Civil Española. Francisca BERNALTE VEGA: La Cultura Anarquista en la República y la Guerra Civil: Los Ateneos Libertarios en Madrid. Tesis Doctoral, Madrid, 1991, p. 148.

${ }^{20}$ La información referente a la solicitud de donativos quedó recogida en el periódico CNT, 7 de agosto de 1933, p. 2. En cuanto al reglamento, CNT, 17 de noviembre de 1933, p. 3. Para actos convocados en la sede ferroviarios, CNT, 30 de septiembre de 1933, p. 3; 14 de octubre de 1933, p. 3; 1 de noviembre de 1933, p. 3.
} 
más relevantes de los ateneos, cargos que desempeñaban los socios. En cuanto a la posibilidad de disolución de uno de estos centros, solo se permitía cuando tenían menos de quince socios ${ }^{21}$.

\section{Ateneo Libertario de Ventas}

Debido a que el objeto de estudio de este trabajo es el análisis de las relaciones interpersonales entre los miembros del Ateneo desde una perspectiva de género; otros factores que pueden ser contemplados como: la represión, la labor socio-cultural y política, etc., serán solo anunciados sin proceder a un análisis más profundo.

La historiografía tradicional aceptó la idea de que la violencia republicana fue protagonizada por los Ilamados "incontrolados"; bajo este epígrafe se escondía un claro prototipo de violento, es decir, un joven, varón y de filiación anarquista ${ }^{22}$. Recientes trabajos están empezando a desmentir esta idea a través de un análisis más exhaustivo que subrayan la heterogeneidad de las personas que participaron en la represión de la zona republicana ${ }^{23 .}$ Este artículo examina dicha hipótesis con materiales nuevos.

Para realizar el análisis de las relaciones interpersonales dentro del Ateneo de Ventas, se ha llevado a cabo una clasificación de los miembros del Ateneo a través de los siguientes criterios: edad, sexo, oficio, filiación y procedencia a través de cuadros, que se muestran a continuación. Se ha hecho mayor incidencia en el análisis de las personas de las que se conocen los cargos que ocuparon, ya que es un condicionante que marca las propias relaciones interpersonales entre los miembros del Ateneo. Finalmente, se han desarrollado tres de los casos más significativos que demuestran, por un lado, el tipo de actividades que se llevaron a cabo en el Ateneo, y por otro lado, muestran las relaciones personales y familiares que se llegaron a establecer en dicho centro. Los criterios seguidos para la elección de estos tres casos han sido, en primer lugar, que son un reflejo de actuaciones conjuntas que implicaban a varios miembros de una misma familia o relaciones personales que se establecieron dentro del Ateneo. El segundo factor de elección, y atendiendo a la perspectiva de género, ha sido la presencia femenina en dichos actos.

Cuadro 1. Edades de los miembros del Ateneo Libertario de Ventas.

\begin{tabular}{|c|c|c|c|c|c|c|c|c|c|c|}
\hline $\begin{array}{c}\text { Edades } \\
\mathbf{1 9 3 6}\end{array}$ & $<\mathbf{2 0}$ & $\mathbf{2 1 - 2 5}$ & $\mathbf{2 6 - 3 0}$ & $\mathbf{3 1 - 3 5}$ & $\mathbf{3 6 - 4 0}$ & $\mathbf{4 1 - 4 5}$ & $\mathbf{4 6 - 5 0}$ & $\mathbf{5 1 - 5 5}$ & $\mathbf{5 6 - 6 0}$ & $\begin{array}{c}\text { Edad } \\
\text { desconocida }\end{array}$ \\
\hline Cantidad & 6 & 7 & 12 & 13 & 7 & 9 & 5 & 2 & 1 & 9 \\
\hline $\begin{array}{c}\text { Cantidad } \\
\%\end{array}$ & $8,4 \%$ & $9,9 \%$ & $16,9 \%$ & $18,3 \%$ & $9,9 \%$ & $12,7 \%$ & $\mathbf{7 \%}$ & $\mathbf{2 , 8 \%}$ & $1,4 \%$ & $12,7 \%$ \\
\hline $\begin{array}{c}\text { Cantidad } \\
\text { Total }\end{array}$ & \multicolumn{10}{|c|}{} \\
\hline
\end{tabular}

Fuente: Consejos de Guerra. AGHDM. Elaboración propia.

\footnotetext{
${ }^{21}$ Francisca BERNALTE VEGA: La Cultura Anarquista..., op. cit., pp.126-148.

22 Julio ARÓSTEGUI: Por qué el 18 de julio..., op. cit.; Javier CERVERA GIL: Madrid en..., op. cit.; Paul PRESTON: EI Holocausto español..., op. cit.

${ }^{23}$ Maria THOMAS: La Fe y la Furia. Violencia anticlerical popular e iconoclastia en España, 1931-1936. Granada, Comares Historia, 2014. p. 100. José Luis LEDESMA VERA: Los días de..., op. cit.
} 
S. GAHETE Y F. JIMÉNEZ, Relaciones personales y de poder en los centros libertarios madrileños.

El caso del Ateneo Libertario de Ventas (verano-otoño de 1936)

Cuadro 2. Distribución por sexos de los miembros del Ateneo Libertario de Ventas.

\begin{tabular}{|l|c|c|}
\hline Sexo & Hombres & Mujeres \\
\hline Cantidad & 54 & 17 \\
\hline Cantidad \% & $76,1 \%$ & $\mathbf{2 3 , 9 \%}$ \\
\hline Cantidad Total & & $\mathbf{7 1 / 1 0 0 \%}$ \\
\hline
\end{tabular}

Fuente: Consejos de Guerra. AGHDM. Elaboración propia.

Cuadro 3. División profesional de los miembros del Ateneo Libertario de ventas.

\begin{tabular}{|c|c|c|c|c|}
\hline $\begin{array}{l}\text { Sector } \\
\text { Profesional }\end{array}$ & Sector Primario & Sector Secundario & Sector Terciario & Sin Sector \\
\hline Trabajo & $\begin{array}{l}\text { Jornalero (8) } \\
\text { Matarife (1) }\end{array}$ & $\begin{array}{l}\text { Albañil (13) } \\
\text { Mecánico (1) } \\
\text { Fumista (1) } \\
\text { Cerámico (1) } \\
\text { Orfebre (1) } \\
\text { Carpintero (1) } \\
\text { Ebanista (1) }\end{array}$ & $\begin{array}{l}\text { Mozo de Almacén (1) } \\
\text { Taquígrafa (1) } \\
\text { Camarero (2) } \\
\text { Tipógrafo (1) } \\
\text { Cartero (1) } \\
\text { Limpieza (2) } \\
\text { Zapatero (1) } \\
\text { Tapicero (1) } \\
\text { Mecánico (1) } \\
\text { Portera (2) } \\
\text { Vendedor de Periódicos (1) } \\
\text { Maestro Armero (1) } \\
\text { Asistenta (1) } \\
\text { Chofer-taxista (1) } \\
\text { Sacristán (1) }\end{array}$ & $\begin{array}{l}\text { Desconocido (18) } \\
\text { Sus Labores (7) }\end{array}$ \\
\hline Total & 9 & 19 & 18 & 25 \\
\hline Total \% & $12,7 \%$ & $26,8 \%$ & $25,3 \%$ & $35,2 \%$ \\
\hline
\end{tabular}

Fuente: Consejos de Guerra. AGHDM. Elaboración propia.

Cuadro 4. Distribución geográfica de los miembros del Ateneo Libertario de Ventas.

\begin{tabular}{|c|c|c|c|c|c|c|c|c|c|}
\hline Provincias & $\begin{array}{c}\text { Madrid } \\
\text { y sus } \\
\text { pueblos }\end{array}$ & Andalucía & $\begin{array}{c}\text { Castilla } \\
\text { la Nueva }\end{array}$ & $\begin{array}{c}\text { Castilla } \\
\text { la Vieja }\end{array}$ & Asturias & Aragón & Extranjeros & Murcia & $\begin{array}{c}\text { País } \\
\text { Vasco }\end{array}$ \\
\hline Cantidad & 20 & 9 & 11 & 4 & 1 & 2 & $\begin{array}{l}\text { Cuba } 2 \\
\text { Chile } 1 \\
\text { Francia } 1\end{array}$ & 3 & 2 \\
\hline Total \% & $35,7 \%$ & $16,1 \%$ & $19,6 \%$ & $7,1 \%$ & $1,8 \%$ & $3,6 \%$ & $7,1 \%$ & $5,4 \%$ & $3,6 \%$ \\
\hline \multicolumn{2}{|c|}{ Cantidad Total } \\
\hline
\end{tabular}

Fuente: Consejos de Guerra. AGHDM. Elaboración propia.

El Ateneo Libertario de Ventas, situado en la carretera de Aragón, no 117, fue creado en septiembre de 1933 como centro cultural. Según declaración, recogida en la Causa General, de la portera del edificio, Isabel Rodríguez del Campo, uno de los locales fue ocupado por miembros de la CNT, antes de la guerra, estableciendo en ella una escuela. Una vez iniciado el conflicto, varios de los 
locales colindantes del mismo edificio quedaron desocupados, siendo ocupados por los miembros del Ateneo. La portera, Isabel Rodríguez, abandonó el edificio, ya que fueron nombrados como porteros/conserjes, miembros del propio Ateneo. Las habitaciones de las plantas superiores fueron ocupadas por José Luis Villaverde y su mujer María Luisa Abadía (conserjes), así como varios de los hermanos de José Luis Villaverde ${ }^{24}$.

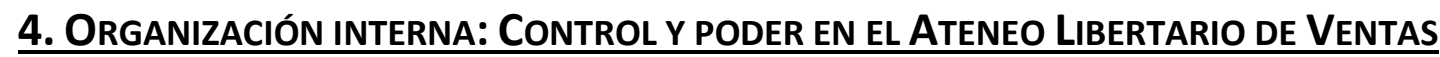

A la hora de analizar las relaciones interpersonales dentro del Ateneo se hace necesario conocer el organigrama interno del mismo y, sobre todo, establecer quiénes fueron los responsables y las personas que ocuparon los cargos de mayor relevancia, en relación con el resto de cargos y personas dentro del Ateneo. Esta serie de datos nos permitirán conocer las relaciones que se establecieron dentro de este centro entre sus diversos miembros, condicionados por las responsabilidades que conllevaba cada cargo, es decir, se considera que los puestos que ocuparon influyeron en la relaciones interpersonales entre los mismos; ya que cada cargo supuso una distribución desigual de poder y una jerarquización interna.

Los cargos de los que se tiene constancia, en el Ateneo Libertario de Ventas, señalan una jerarquización entre sus miembros, es decir, una distribución desigual del poder. Los puestos que se han podido conocer a través de las fuentes son muy diversos. Los más destacados fueron los del Equipo Directivo, ya que dirigían las funciones del Ateneo. Entre los cargos que lo compusieron, y de los que se ha podido concretar las personas que los ocuparon, encontramos a diferentes responsables que desempeñaron funciones como la de Presidente o Secretario. También, se han encontrado puestos intermedios, como los guardias o los conductores, y otros con menor poder de decisión, tales como los servicios de limpieza y cocina. Cada uno de estos puestos conllevó un tipo de responsabilidades y una serie de funciones, que limitaban a aquellas personas que los ejercían.

Cuadro 5. Cargos conocidos en el Ateneo Libertario de Ventas.

\begin{tabular}{|l|l|}
\hline Cargos & Cantidad \\
\hline Presidentes & 5 \\
\hline Guardias & 6 \\
\hline Conserjes & 1 \\
\hline Mecanógrafas & 4 \\
\hline Cocina. & 2 \\
\hline Limpiadoras & 2 \\
\hline Chófer & 5 \\
\hline Actividades Culturales & 2 \\
\hline Múltiples funciones & $\begin{array}{l}\text { Limpiadora, cocinera y conserje 1 } \\
\text { Dirigente, registros, incautaciones, 1 }\end{array}$ \\
\hline Sin cargo específico & 26 \\
\hline Total & \\
\hline
\end{tabular}

Fuente: Consejos de Guerra. AGHDM. Elaboración propia.

\footnotetext{
${ }^{24}$ Causa General de Madrid, caja. 1530, expediente, 13, pieza sobre checas (Ateneo Libertario de Ventas), p. 72.
} 
En primer lugar, vamos a hablar de lo que las fuentes han catalogado como presidente del Ateneo, y así se ha mantenido en este trabajo (cuadro 5), y que fueron, en realidad, las personas que tuvieron un cargo en los diversos comités que formaban el Ateneo. Dentro del Ateneo Libertario de Ventas se han encontrado tres tipos de comités: comité de defensa, encargado de la labor represiva; comité de abastos, encargado de repartir a la población de la barriada a través de vales, comida y ropa, fruto de las incautaciones; y comité cultural encargado de realizar diversas tareas relacionadas con la educación. A continuación, se procederá a analizar los cinco expedientes encontrados referentes a los presidentes del Ateneo. Todo Ateneo contó con un reglamento que favoreciese el buen funcionamiento del mismo. No obstante, no se ha podido consultar el del Ateneo Libertario de Ventas, ya que no se ha localizado, pero sí el de otros ateneos como el del Ateneo Libertario de Vallecas, instalado durante la contienda en la calle Emilio Ortuño no 11. En dicho reglamento se crearon diversos cargos de responsabilidad, como vocales, contador, bibliotecario, tesorero o el de vicesecretario, siendo el de mayor importancia el de Secretario. Todos ellos, cargos anuales que ocupaban los socios y socias si eran elegidos por sus compañeros y compañeras. Solo se nombraba presidente en los casos en los que se formaba la Asamblea General, encargada de resolver aspectos específicos del funcionamiento del ateneo. Esta asamblea se reunía mensualmente y los socios o socias que ocupaban los cargos cambiaban en cada reunión ${ }^{25}$.

Ante la situación generada por el golpe de Estado del 18 de julio, el Ateneo Libertario de Ventas asumió una serie de nuevas funciones como la de orden público y la labor de abastecimiento. No obstante, mantuvo e incluso amplió su función cultural dentro de la barriada. La organización de todas estas actividades requirió la formación de una serie de órganos para dar respuesta a la nueva situación. Dentro de estos órganos se creó una jerarquía de cargos entre los que destacó el de presidente de cada uno de los tres comités mencionados anteriormente. El primero de los presidentes del que se tiene constancia que actuó dentro del comité de abastos fue Antonio Salinas Hernández ${ }^{26}$, militante de la CNT (dentro del ramo de la construcción), de 41 años en 1936, y casado con Josefa Sánchez Jiménez, cocinera en el Ateneo. La función de este comité fue el reparto de vales canjeables en el Ateneo por ropa y comida, obtenidas éstas en las requisas y saqueos. Tras su paso por este centro desempeñó el cargo de delegado/concejal del Ayuntamiento de Canillas. Otra persona de relevancia en el comité de abastos fue Julián Antón Jerez, acusado de haber sido el administrador general de todas las alhajas y dinero obtenido de las requisas e incautaciones ${ }^{27}$.

Uno de los presidentes del comité de defensa fue Juan Carmona Campillo, alias "el matón" ${ }^{28}$. Su hermano, Gabriel, la mujer de éste, Josefa Paredes y las tres hijas de éstos formaban también parte del Ateneo. Magdalena Ávila, mecanógrafa del Ateneo, también estuvo relacionada con Juan Carmona, ya

\footnotetext{
${ }^{25}$ Centro Documental de la Memoria Histórica, Caja 1019, Expediente 3. Hay fuentes que sí hablan de la existencia del cargo de presidente como persona rectora de la actividad del ateneo. Francisca BERNALTE VEGA: La cultura anarquista..., op. cit., pp. 126-129. Sin embargo, dado que los órganos administrativos, los diversos comités, que se crearon en los ateneos fueron fruto de una situación inesperada, surgidos a través de la improvisación y de la inmediata experiencia, es posible que existiera realmente la figura de presidente en estos comités.

${ }^{26}$ Archivo General Histórico de Defensa: sumario, 13233, caja, 1714, no 7; sumario, 104630, legajo, 5960.

${ }^{27}$ AGHD: sumario, 141414, legajo, 8126.

${ }^{28}$ AGHD: sumario, 107812, legajo, 4766.
} 
que mantuvieron una relación sentimental. Este es un ejemplo de las estrechas relaciones personales existentes en el Ateneo. A Juan Carmona se le relacionó con su participación en distintas ejecuciones, lo que hizo que en diversos sectores del barrio se le conociera como "el verdugo del Ateneo". Uno de los casos más significativos es una acusación contra él, en la que se establece que Juan Carmona asesinó a un miliciano que se encontraba realizando guardias en el Ateneo por tener "actitudes obscenas" con un chico. Esto sería un ejemplo de que la estricta moral de la época era reproducida incluso en grupos de izquierdas. Hay que mencionar que el tema de la homosexualidad aunque fue objeto de debate entre los grupos anarquistas, la posición adoptada fue la de considerarla como una <<inversión sexual»>. No obstante, se afirmaba que no había nada de inmoral en la homosexualidad y que, por tanto, ésta no debía ser castigada ${ }^{29}$.

Un socio del Ateneo que compartió funciones con Juan Carmona fue Antonio Hurtado Fajardo, alias "el Chato", de 30 años en $1936^{30}$. Ocupó un alto cargo dentro del comité de defensa, fue juez del mismo, y se le relacionó con distintas incautaciones y asesinatos. Después de la guerra fue denunciado por haber acosado a mujeres de la barriada, a quienes amenazaba con pistola.

Otro alto cargo del comité de defensa fue José Muñoz de la Fuente, militante de la $\mathrm{CNT}^{31}$. Su caso es otro ejemplo de las relaciones familiares dentro del Ateneo, ya que su padre, Fermín Muñoz Tejada y sus dos hermanas, Pilar y Mercedes Muñoz de la Fuente, fueron también miembros del Ateneo. José Muñoz tenía 35 años en 1936 y pertenecía al Ateneo desde antes de la guerra. Manifestó un compromiso sindical al participar en la revolución de octubre de 1934. Junto a su hermana Pilar Muñoz de la Fuente, fueron acusados de diversos asesinatos. En el segundo expediente se le acusó también de dirigir las milicias para realizar requisas, saqueos, propaganda e incitar a los jóvenes a alistarse.

Se han encontrado indicios de que José Luis Villaverde Petralanda ${ }^{32}$, estuvo también relacionado con la dirección del Comité de defensa del Ateneo, debido a su larga trayectoria dentro de la CNT. No obstante, las fuentes lo relacionan con el servicio de conserjería, cargo del que no se tiene constancia de que existiera, tal y como demuestran los reglamentos de otros ateneos libertarios, como el ya comentado de Vallecas. Otro indicio de la relevancia que tuvo José Luis Villaverde dentro del Ateneo es su posterior nombramiento como concejal en el Ayuntamiento de Canillas ${ }^{33}$. Durante su estancia en el Ateneo se le relacionó con distintas ejecuciones en el Cementerio del este. En su expediente fue acusado de formar parte de los piquetes de ejecución en el Cementerio del este. No obstante, no se ha probado la existencia de piquetes permanentes en este cementerio y en otros lugares de la retaguardia madrileña, donde se llevaron a cabo estas ejecuciones. Las ejecuciones

\footnotetext{
${ }^{29}$ Martha ACKELSBERG: Mujeres Libres..., op. cit., p. 61.

${ }^{30}$ AGHD: sumario, 1414, legajo, 8126; sumario, 107812, legajo, 4766.

${ }^{31}$ AGHD: sumario, 52621, legajo, 5667 y legajo, 7815.

${ }^{32}$ AGHD: sumario, 107812, legajo, 4766, sumario, 10760, caja, 2077, no 10.

33 Las personas que ocuparon cargos importantes en este tipo de organismos, paralelos a las instituciones legalmente constituidas por la República, acabaron siendo incorporados a estas últimas como forma de recuperación del poder perdido tras el golpe de estado. Un ejemplo de socio del Ateneo que fue concejal fue Antonio Salinas Hernández, con cargo de responsabilidad dentro del Ateneo antes de que se introdujese en las instituciones republicanas.
} 
denominadas "paseos" se realizaron recurriendo a milicianos de los centros que los llevaron a cabo o recurriendo a milicianos que se encontraban en controles cercanos.

Las profesiones que ocuparon las mujeres dentro del Ateneo, responden a aquellos puestos que según la concepción de la época se adaptaban "a lo femenino", como: mecanógrafas, limpiadoras y cocineras. Durante el siglo XIX, especialmente, no estuvo bien visto que las mujeres trabajasen fuera de su hogar, y sobre todo, si éstas estaban casadas, ya que se entendía que el trabajo único de la mujer debía estar en su hogar y en el cuidado de la familia. No obstante, la situación económica hizo que las mujeres de clase trabajadora, aun casadas y con hijos, tuviesen que trabajar, fundamentalmente, en las fábricas, como limpiadoras, cocineras o cuidadoras. En el siglo XX, y debido a la modernización progresiva que iba teniendo lugar aparecieron nuevos puestos de trabajo como las mecanógrafas o las telefonistas, que solían ocupar mujeres jóvenes tras unos estudios iniciales que las capacitaban para el cargo, y que normalmente solían abandonar al contraer matrimonio.

Uno de estos nuevos cargos fue ocupado por Magdalena López Salamanca, una joven de 21 años en 1936 que ejerció como mecanógrafa del Ateneo desde mediados de septiembre de 1936 hasta enero de 1937. Según su propia declaración, perteneció al Comité de defensa, comité al que pertenecía Julián Hernández Montero con el que las fuentes establecen que tuvo una relación sentimental. Otra mujer que ocupó el cargo de mecanógrafa fue Concepción Domínguez, también de 21 años en 1936, y relacionada con la organización Mujeres Libres. Según su propia declaración fue mecanógrafa desde agosto-septiembre de 1936 hasta finales de 1937. Ella perteneció al Comité de abastos, cuyo jefe fue Julián Antón. En su declaración, alegó que perteneció al Ateneo como forma de mantener a su familia y comprobar si perseguían a su padre, de tendencias derechistas. La tercera mujer de la que se tiene constancia que ejerció el puesto de mecanógrafa fue Pilar Bravo Montero ${ }^{34}$, relacionada sentimentalmente con Martín Martínez Conesa, también miembro del Ateneo. Pilar Bravo Montero fue acusada de realizar incautaciones y de su pertenencia a la UGT, ya que antes del inicio de la guerra trabajaba en una empresa de lámparas ${ }^{35}$.

A pesar de que las tareas de mecanografía se adjudicaron en su mayoría a mujeres, en este centro se ha encontrado un caso en el que este trabajo fue ejercido por un hombre, José Rodríguez Moreno, quien también fue acusado de intervenir en registros, asesinatos, saqueos y de realizar denuncias $^{36 .}$

Tras el golpe de estado se realizaron por Madrid incautaciones de vehículos con el objetivo de obtener una mayor movilidad de personas y de víveres. Esta situación generó la necesidad de conductores que llevasen a cabo estas tareas. En lo que respecta al Ateneo Libertario de Ventas se han encontrado hasta seis expedientes de personas que realizaron labores de conducción. Uno de ellos fue Vicente Luis Aragones, conductor de la sección de abastos ${ }^{37}$. En su declaración alegó que realizó estas

\footnotetext{
${ }^{34}$ AGHD: sumario, 141414, legajo, 8126.

${ }^{35}$ Según el reglamento del Ateneo libertario de Vallecas, cualquier persona, independientemente de su filiación política o sindical, podía ingresar como socio o socia en el Ateneo. Por ello, no es de extrañar la coexistencia de personas de filiación socialista o comunista dentro del ateneo. CDMH, Caja 1019, Expediente 3.

${ }^{36}$ AGHD: sumario, 50170, legajo, 5729.

${ }^{37}$ AGHD: sumario, 13839, legajo, 4568.
} 
tareas durante dos meses porque quería recuperar su vehículo, el cual le fue incautado por los milicianos del Ateneo.

Otra de las personas a las que se relacionó con las labores de conducción fue Ángel del Castillo del $\mathrm{Amo}^{38}$, quien se incorporó como conductor del Ateneo en los primeros días de la guerra, realizando labores nocturnas de traslado de presos ${ }^{39}$. Junto a Ángel del Castillo estuvieron otros conductores como fue el caso de Lucio Calvo Rodríguez ${ }^{40}$, Conrado Quing, perteneciente al Comité de abastos, y Antonio Barreiro López ${ }^{41}$, quien además de conducir en Madrid, condujo en pueblos de Guadalajara y Cuenca ${ }^{42}$.

La guerra generó la necesidad de adoptar nuevas medidas como forma de protección. En el caso de los ateneos, esta necesidad se tradujo en la creación de una serie de puestos de vigilancia y seguridad, ocupados por milicianos, divididos en turnos o guardias. Dentro del Ateneo de Ventas desempeñaron este tipo de funciones, Juan Quesada Pastor ${ }^{43}$, portero del edificio que ocupaba el Ateneo, y posteriormente soldado en el IV Batallón ${ }^{44}$. Otros guardias fueron Ángel Palomares Sánchez ${ }^{45}$, alias "el sillero" y Felix Molina Palencia ${ }^{46}$, aunque este último afirmó haber realizado guardias en las colas que se formaban en el Ateneo durante los repartos de ropa y alimento. Asimismo, dijo que en septiembre de 1936, fue nombrado ranchero en el frente por lo que estuvo en el Ateneo entre 10 y 12 días en el turno de tarde.

De los otros tres guardias de los que se tiene constancia son: Julián Garrido Navarro/Morales ${ }^{47}$, Bonifacio Álvarez $\operatorname{Ortiz}^{48}$, quien al comenzar la guerra acudió al Ateneo donde le dieron un fusil para

${ }^{38}$ AGHD: sumario, 2021, legajo, 2886. En este expediente se encuentran dos declaraciones del acusado. En la primera, el encausado confiesa crímenes, asesinatos y demás actividades cometidas por él en el Ateneo, para pasar a retractarse en la segunda confesión, donde no niega los hechos relatados en la primera declaración sino que acusa a los hermanos Salinas, los hermanos Villaverde y a Gabriel Carmona Campillo de haberlos cometido, limitándose él a conducir.

${ }^{39}$ Este tipo de actividades se conocieron con el sobrenombre de "paseos" y consistieron en el traslado de uno o varios detenidos en un vehículo con milicianos armados que ejecutaron a los detenidos en lugares apartados. Para más información sobre los paseos, léase Javier CERVERA GIL: Madrid en..., op. cit., pp. 72-82.

${ }^{40}$ AGHD: sumario, 3037, legajo, 4610, sumario, 10145, legajo, 5008, sumario, 141414, legajo, 8126.

${ }^{41}$ AGHD: sumario, 107812, caja, 501, no 4.

${ }^{42}$ El traslado de milicianos fue común en los meses de guerra, ya que se produjo una gran capacidad de movilidad física gracias a las incautaciones de vehículos o el traslado de tropas. Con esta movilidad apareció el prototipo de miliciano foráneo, que actuó en incautaciones y detenciones. Para más información acerca de esta cuestión léase: Maria THOMAS: La Fe y la Furia..., op. cit., pp. 210-218.

${ }^{43}$ AGHD: sumario, 141414, legajo, 8126, sumario, 49320, caja, 881, no 1.

${ }^{44}$ Una forma de controlar a todos aquellos grupos y comités que se formaron a raíz del golpe de estado fue la inclusión de los milicianos y milicianas en las organizaciones republicanas. Aquellos que más se distinguieron los introdujeron en la vida política a través de cargos en los ayuntamientos o en los servicios de seguridad y vigilancia, como la policía. A los militantes de base que desempeñaron funciones de poca relevancia en los nuevos órganos de poder los destinaron al ejército.

${ }^{45}$ AGHD: sumario, 54773, caja, 1688, no 1.

${ }^{46}$ AGHD: sumario, 141414, legajo, 8126.

47 ibídem. No queda claro cuál de los dos apellidos es el correcto. En el expediente se manejan ambos indistintamente. 
realizar guardias. Sus hijos también tuvieron relación con este centro. Por último, Alejandro Blanco Velasco ${ }^{49}$, el cual no solo realizó guardias en el Ateneo sino que también fue acusado de participar en la composición de controles de carreteras con la función de detener y registrar a todos los coches y a todas las personas que circulaban. Realizó este tipo de actividades hasta el 8 de octubre de 1936, fecha en la que fue al frente. A raíz de la declaración de Alejandro Blanco Velasco se menciona a una mujer, Isidora Mula, que tras un registro en la casa donde trabajaba se unió al Ateneo realizando también guardias. La imagen de la miliciana con mono y, sobre todo, con pistola fue un prototipo femenino que a pesar de ser representado por una escasa proporción de mujeres, fue extendido como algo generalizado en la retaguardia. Esta imagen rompía los esquemas que sobre la "feminidad" y lo "femenino" se tenían en el momento y constituyó un símbolo de mujer emancipada y libre, comprometida con la defensa de la libertad. La realidad de las mujeres milicianas fue mucho más compleja y difícil teniendo que hacer frente a múltiples obstáculos, consecuencia de las rígidas concepciones que sobre lo "masculino" y lo "femenino" se tenía en el momento. Acabada la guerra, el hecho de haber vestido mono y llevar pistola constituyó un motivo de acusación, ya que lo identificaban como un elemento subversivo del modelo femenino tradicional, defendido por los sublevados.

Durante la guerra la alimentación fue un problema al que tuvo que hacer frente la sociedad madrileña. En este sentido, la labor de manutención fue muy importante y estos centros se hicieron cargo de ella como forma de obtener prestigio y poder dentro del barrio. El Ateneo incorporó a personal que se hiciera cargo de estas tareas, encontrándose entre ellas a Josefa Sánchez Jiménez, relacionada con Mujeres Libres y casada con Antonio Salinas, uno de los responsables del Ateneo. Fue acusada de la incautación de las alhajas que se encontraron en el domicilio de Maria Luisa Abadía, miembro del Ateneo. Sin embargo, ella lo negó y defendió que perteneció a este centro por obligación de su marido, entrando en agosto de 1936, pero que ante el maltrato que ejercía éste sobre ella, abandonó el Ateneo a los dos meses.

Entre las funciones que el Ateneo mantuvo tras el golpe de estado se encuentran las actividades culturales y de instrucción. Este tipo de labores nunca fueron constitutivas de delito durante la República; sin embargo, acabada la guerra sí lo fueron. Por ello, fue acusada Victoria Gómez Núñez ${ }^{50}$, aunque ella niega haber realizado ningún tipo de actividad dentro del Ateneo. En declaraciones de Josefa Sánchez y Maria Luisa Abadía, miembros del Ateneo, alegaron que ella solo acudía para recibir clases y no para darlas ${ }^{51}$. Relacionado con las actividades culturales cabe destacar a Félix Ruiz Mota ${ }^{52}$, que perteneció al Ateneo como secretario del comité de cultura en 1937.

Otra de las actividades que se mantuvo durante la guerra fue la labor de limpieza, en este caso, solo se ha encontrado a mujeres que ocuparon este puesto. Entre ellas, Mercedes Muñoz de la

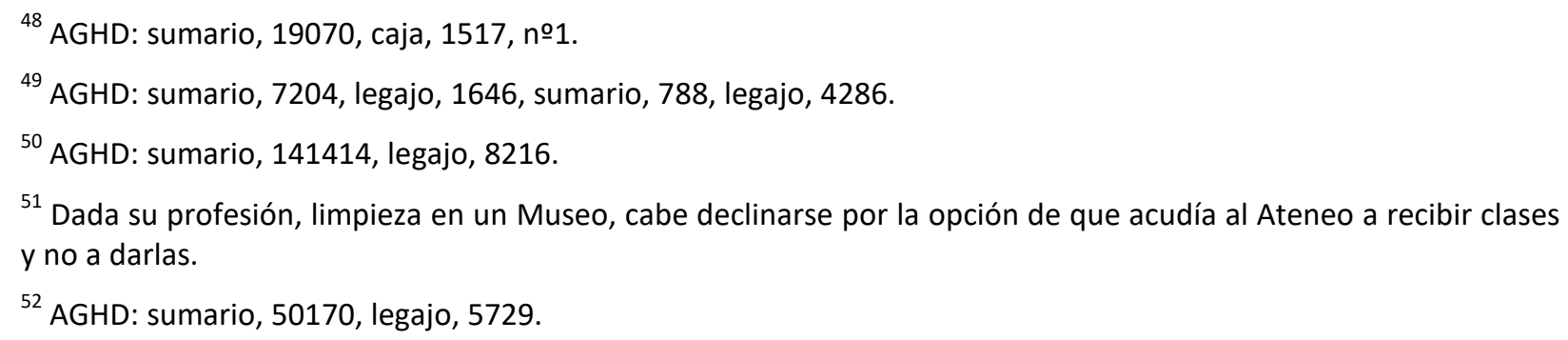


Fuente ${ }^{53}$, de 22 años en 1936, y a quien las fuentes, y ella misma en su declaración lo afirma, acusan de llevar mono y pistola. También fue acusada de ir al frente de Sigüenza aunque ella lo negó. Su padre, Fermín Muñoz Tejada, su hermana, Pilar Muñoz de la Fuente y su hermano José, así como su marido José Iglesias Salinas, con el que se casó durante la guerra, pertenecían al Ateneo. Otra de las mujeres de las que se tiene constancia que ejercieron labores de limpieza fue Matilde Matesanz Fernández ${ }^{54}$, quien desempeñó estas tareas de septiembre a octubre de 1936 para el Comité de abastos. Recibió por ello 10 pesetas diarias más manutención.

Un caso relevante dentro del Ateneo fue el representado por Maria Luisa Abadía ${ }^{55}$, de 29 años en 1936, y casada con José Luis Villaverde Petralanda, conserje/secretario del Ateneo. La importancia de este caso reside en la multiplicidad de funciones que desempeñó en el Ateneo, por un lado, como cocinera y limpiadora, y por otro lado, ejerciendo funciones de mayor rango como fueron las de conserjería/portería al sustituir a su marido en el puesto. No obstante, negó haber ejercido labores de conserjería y afirmó que las tareas de cocina las ejerció solo durante mes y medio. El resto del tiempo se dedicó a funciones de limpieza en la planta baja, donde se situaba la biblioteca. Al igual que Mercedes Muñoz de la Fuente fue acusada de vestir mono y llevar pistola.

\section{Personas relacionadas con el Ateneo}

Debido al carácter represivo de las fuentes consultadas y el momento histórico en el que fueron elaboradas, plena represión franquista, éstas no son muy exhaustivas a la hora de indicar cargos, meses de participación en el Ateneo, servicios prestados, etc. El único interés que persiguieron este tipo de fuentes fue averiguar qué tipo de delitos cometieron los y las encausados/as con especial énfasis en los asesinatos a personas de derechas, y saqueos a propiedades privadas.

Por tanto, se hace muy difícil la reconstrucción del Ateneo en cuanto a cargos, servicios que se llevaron a cabo, funciones y ocupaciones de cada integrante del Ateneo. Sólo en las personas anteriormente señaladas se especifican los cargos que ocuparon. Del resto se procede a acusarlos/as de saqueos, asesinatos, registros, detenciones y pertenencia al Ateneo, sin especificar ni cargos, ni funciones.

Ante el gran número de casos encontrados en esta situación de indefinición de su cargo o sus funciones, se va a proceder a señalar a las personas que participaron en ciertos acontecimientos, determinados por las relaciones personales como la amistad, la actuación conjunta, etc., nombrándose así diversas funciones que se realizaban en el Ateneo sin poder unirlas con un cargo específico.

Se han seleccionado tres casos para poder analizar las relaciones interpersonales dentro del Ateneo Libertario de Ventas. El primero de ellos está representado por un sacristán y dos mujeres. EI segundo caso protagonizado por la familia Muñoz de la Fuente, un ejemplo de la fuerza de las

\footnotetext{
${ }^{53}$ AGHD: sumario, 52621, legajo, 7815.

${ }^{54}$ AGHD: sumario, 54773, caja, 1688, № 1.

${ }^{55}$ AGHD: sumario, 141414, legajo, 8126.
} 
relaciones familiares dentro del Ateneo. Y por último, el tercer caso, llevado a cabo por una joven de dieciséis años.

\section{CASO PRIMERO: EL SACRISTÁN Y SUS DOS COLABORADORAS}

Pablo Sarroca Tomás ${ }^{56}$, capellán mayor del ejército, según declaración suya en la Causa Genera $^{57}$, formó parte del Ateneo desde el 16 de septiembre de 1936 hasta el 4 de junio de 1937 . Un aspecto cuanto menos llamativo, ya que representaba a dos grupos catalogados como enemigos por los defensores de la zona republicana, sacerdote y militar. Los militares por ser los promotores del golpe de estado y el personal religioso, por considerarlo aliado de los primeros ${ }^{58}$. Aun así, venció las resistencias de los socios y socias del Ateneo y participó codo con codo con los mismos. Además, tuvo una cierta relevancia fuera del Ateneo, ya que ocupó cargos en el negociado de Servicios Especiales del Ministerio de la Guerra, primero como censor de correspondencia y, posteriormente, como interrogador. No obstante, esta visibilidad no impidió que fuese detenido por los Tribunales Populares, acusado de haber cometido un asesinato, no por su condición de sacristán.

Las funciones con las que se le relacionó en el Ateneo Libertario de Ventas fueron las de realizar denuncias e incluso ordenar a los milicianos del Ateneo ir a detener a aquellas personas que denunciaba. En esta labor le ayudaron dos mujeres, Gregoria Rubio Acosta, apodada "la Huesos" ${ }^{59}$ y Julia Redondo Herrero ${ }^{60}$. Gregoria Rubio Acosta miliciana, que vistió el mono y llevó pistola, según las fuentes franquistas, al servicio del Comité Revolucionario de Canillejas (órgano de gestión y administración del Barrio de Canillejas, que se formó con el apoyo de todas las fuerzas políticas y sindicales que lucharon contra los sublevados, en un intento de sustitución de la autoridad republicana, el Ayuntamiento, por considerar que estaba agotado y que respondía a intereses burgueses). No obstante, también tuvo relación con el Ateneo Libertario de Ventas, desempeñando labores de orden público, a través de registros y detenciones. Para el Ateneo también trabajaba su compañero sentimental, José del Pozo. Similares funciones desempeñó Julia Redondo Herrero, acusada por las fuentes franquistas de realizar registros y detenciones, pero que también se la relacionó, junto a Gregoria Rubio Acosta, de ser una de las mujeres causante de la quema de imágenes religiosas de la Iglesia del barrio, la Concepción. Asimismo, se las relacionó a ambas con el asesinato de la familia

\footnotetext{
${ }^{56}$ AGHD: sumario, 141414, legajo, 8126; sumario, 2640, caja, 3188.

${ }^{57}$ Causa General de Madrid, caja. 1530, expediente, 13. Pieza sobre Checas (Ateneo Libertario de Ventas), p. 39.

${ }^{58}$ No obstante, el anticlericalismo no fue un sentimiento ligado a una ideología, sino un largo proceso temporal interclasista e intergeneracional. Desde finales del siglo XIX, pero, sobre todo, durante el primer tercio del siglo XX, diversos sectores de la población percibieron un acercamiento entre las elites y los religiosos, una intromisión cada vez mayor en la vida doméstica, a través del confesionario, y en la esfera pública, a través de manifestaciones y actos litúrgicos al aire libre. También se vio en la figura de los religiosos masculinos una amenaza de inversión de roles masculinos y femeninos, ya que tanto por la vestimenta como por los sentimientos que predicaban fueron considerados como elementos femeninos, pero en último término, su cuerpo era masculino. Todos estos procesos, intercalados, señalaron a los religiosos como aliados de los sublevados, por lo que fueron concebidos como enemigos.
}

${ }^{59}$ AGHD: sumario, 103357, caja, 20480, no 1.

${ }^{60}$ AGHD: sumario, 107812, caja, 501, no 4. 
Arellano. El marido de Julia Redondo Herrero, al igual que ella, formó parte del Ateneo, sin embargo, se desconocen los datos personales del mismo.

La relación de Gregoria Rubio Acosta y Julia Redondo Herrero con el sacristán Pablo Sarroca Tomás proviene de cuando los tres coincidieron en el Ateneo Libertario de Ventas. Ambas fueron las encargadas de llevar a Pablo Sarroca los partes de los asesinatos cometidos por dicho centro. Se desconoce si realizaron más labores juntos, o si los registros y detenciones que se les imputaron a Gregoria Rubio Acosta y Julia Redondo Herrero fueron los que se dijeron que ordenaba Pablo Sarroca Tomás. No obstante, el encontrar dos milicianas que desempeñaron labores de orden público y un sacristán que actuó de forma conjunta con ellas, es cuanto menos llamativo, ya que ellas fueron destinadas a labores asistenciales y el personal religioso fue considerado cómplice de los militares sublevados. Sin embargo, y con relación a los cargos que ocuparon cada uno, se mantiene una relación jerarquizada donde Pablo Sarroca Tomás, varón, ostentó un puesto de mayor relevancia que el de sus compañeras mujeres y donde, él ordenaba y ellas cumplían. Manteniéndose, de nuevo, una relación vertical y no horizontal.

\section{CASO SEgUndo: LA FAMILIA MUÑOZ dE LA FUENTE}

Otro caso significativo fue el llevado a cabo por la familia Muñoz de la Fuente, integrado por el padre, Fermín Muñoz Tejenas, sus dos hijas, Pilar y Mercedes Muñoz de la Fuente ${ }^{61}$ y su hijo, José Muñoz de la Fuente ${ }^{62}$. Dentro de esta familia el que tuvo una actuación más significativa dentro del Ateneo fue José Muñoz, a quién las fuentes relacionan como secretario del Ateneo antes de la guerra. Durante la guerra siguió actuando dentro del Ateneo, acusado de realizar asesinatos, detenciones y registros, actos llevados a cabo junto a su hermana Pilar. En el caso de Pilar Muñoz de la Fuente se le acusa directamente de la ejecución de una familia entera e incluso se la relaciona con afirmaciones como: "antes de que mi marido cogiese el fusil, yo ya estaba cansada de matar". Este aspecto es significativo, ya que es el único caso encontrado, en el que una mujer es acusada del hecho material de ejecutar. Lo más significativo de que una mujer fuese la que realmente llevase a cabo la ejecución está en esa superioridad de poder que le otorgaba el tener un arma y tener la capacidad de usarla. De ahí se deduce la transgresión que supondría que una mujer ostentase ese poder, y especialmente, cuando lo ejercía sobre un hombre. Se desconoce, si su marido formó también parte del Ateneo.

En cuanto al padre, Fermín Muñoz Tejenas y su hija Mercedes Muñoz de la Fuente, el primero fue confidente del Ateneo y acomodador de un cine del que se incautó el Ateneo. De Mercedes solo se especifica su función en el servicio de limpieza dentro del Ateneo.

Se ha escrito sobre este caso por su trascendencia con respecto a la importancia de los vínculos familiares dentro del Ateneo, ya que encontramos a un padre con tres de sus hijos. En este caso, la persona que tuvo una mayor implicación dentro de este centro fue José Muñoz de la Fuente, al que se le relacionó con la cúpula directiva del Ateneo. Es significativo que frente a su hermano, Pilar y Mercedes Muñoz de la Fuente ejercieran labores de menor relevancia, aun siendo de la misma familia,

\footnotetext{
${ }^{61}$ AGHD: sumario, 52621, legajo, 7815.

62 ibídem. AGHD: sumario, 52621, legajo, 5667.
} 
ya que su hermano podría haber influido a favor de sus hermanas para la ostentación de cargos con mayor relevancia.

\section{Caso tercero: María González Saez, una joven comprometida con la causa} LIBERTARIA

Otro de los casos a destacar es el de María González Saez ${ }^{63}$ que con dieciséis años en 1936, fue acusada de participar en registros, detenciones, incautaciones, etc. Se establece que estuvo en el frente, donde fue herida. Vistió el mono de miliciana e iba armada. Se la relacionó con las principales cabezas del Ateneo, especialmente con José Luis Villaverde Petralanda y su mujer Maria Luisa Abadía, con quienes mantuvo una relación de amistad. De hecho, en su expediente se afirma que llegó a ser dirigente del Ateneo, hipótesis poco creíble, por la posición secundaria que en dicho centro ocuparon las mujeres, tal y como se ha ido constatando a lo largo de este trabajo. Su relación con los principales responsables del Ateneo, pudo llevar a hacer dicha afirmación. No obstante, en los estatutos del Ateneo de Vallecas se afirma que cualquier socio, independientemente de su sexo, podría ocupar cualquier cargo dentro del centro, incluido los del Equipo Directivo ${ }^{64}$.

Las fuentes relacionan a María González con su cuñado, Segundo Gamo, miembro del Ateneo, y con quien habría realizado los registros de los que se le acusan. Su madre María Saez García también formó parte del Ateneo aunque se desconocen en ambos casos cuales fueron sus funciones dentro de dicho centro.

Asimismo, fue acusada de participar en una de las incautaciones llevadas a cabo por el Ateneo como la de la finca del Conde de Romanones junto a otros compañeros. Otras incautaciones relevantes dentro de la barriada, y protagonizada por personal al servicio del Ateneo, fueron las de la farmacia y otras propiedades de la familia Ferreres, la finca de Campo real, el Hotel "Mi Huerto" ${ }^{65}$, en el mismo barrio de Ventas, el bar la Rioja en el no 177 de la carretera de Aragón, donde instalaron el noveno comité de la Cruz Roja. Otra de las incautaciones fue el edificio no 115 de la carretera de Aragón, el cual fue utilizado como almacén.

Dentro de los expedientes de mujeres este es el más denso en cuanto a volumen documental y en el que con más detalle se describe los supuestos actos que cometió y por los cuales fue acusada. Sorprende, especialmente, la edad de María González, dieciséis años y, en este caso, con una importante participación dentro del Ateneo lo que contrasta con la actuación menos representativa del resto de mujeres localizadas en el Ateneo Libertario de Ventas. No obstante, tampoco llegó a ocupar cargos de control dentro del Ateneo, ni tuvo a su disposición compañeros subordinados a sus órdenes. Asimismo, no ha quedado referencia de que tras su paso por este centro desempeñara actividades de responsabilidad dentro de otras agrupaciones políticas.

\footnotetext{
${ }^{63}$ AGHD: sumario, 10861, legajo, 4229.

${ }^{64} \mathrm{CDMH}$, Caja 1019, Expediente 3.

${ }^{65}$ Hotel considerado en la Causa General como "Checa” relacionada con el Ateneo Libertario de Ventas. Ministerio de Justicia: Causa General. La dominación roja en España, Madrid, Ministerio de Justicia, 1943, pp. 84-90.
} 
Sin embargo, comparada con el resto de sus compañeros varones, no desempeñó ninguna función de control dentro del Ateneo, ni tuvo a su disposición compañeros subordinados a sus órdenes. Al igual que, tras su paso por este centro, no desempeñó labores de responsabilidad dentro de otras agrupaciones.

\section{CONCLUSIONES}

La documentación consultada ha permitido reconstruir el Ateneo Libertario de Ventas, conociendo cargos, organización y personas que formaron parte de él. Este estudio nos proporciona un mayor conocimiento sobre las relaciones interpersonales entre miembros pertenecientes al anarquismo y nos permite contraponerlo con sus ideas en torno a la comunidad. También ha sido útil para analizar de forma más pormenorizada las relaciones que en un centro de ideología anarquista se dieron entre mujeres y hombres. Asimismo es importante conocer este tipo de centros desde dentro por la relevancia que tuvieron en los primeros meses de la guerra, a la hora de organizar las barriadas en las que se encontraban.

El tipo de fuente que ha sido consultada para realizar este estudio han sido los Consejos de Guerra. Esta documentación persigue como único objetivo la inculpación de los encausados, ya sea por delitos ficticios o reales. De hecho, el pertenecer al Ateneo ya era considerado como un delito, independientemente de las funciones realizadas en el centro. De esta forma, la información analizada afecta a los resultados de esta investigación, ya que, por ejemplo, no se dice nada de posibles motivaciones de los encausados para saber por qué actuaron de esa determinada manera y cómo respondieron emocionalmente a las diversas situaciones que vivieron.

La crítica de fuentes se hace fundamental para el análisis de estos documentos debido a que el objetivo de estas fuentes fue culpar a los detenidos y detenidas de los supuestos delitos por lo que fueron denunciados. Todo ello dentro de un proceso represivo franquista donde se falsearon datos y pruebas, donde se recurrió a la violencia física y verbal, es decir, la tortura para la obtención de testimonios o, simplemente, la firma del acusado/a de una declaración que había sido escrita a través de los testimonios de los vecinos y vecinas adeptas al régimen. Además hay que añadir la indefensión de los acusados/as cuando simples rumores eran considerados prueba suficiente para juzgar a una persona, convirtiéndose así también en una herramienta de resolución de conflictos personales generados antes de la guerra o durante la misma. Por todo ello, es conveniente cruzar la información con la facilitada con otras fuentes, y situar todo el proceso en su contexto.

Dentro de los objetivos que guiaron este trabajo se ha podido constatar, por un lado, que las relaciones de género que se desarrollaron en el Ateneo, mantuvieron muchos de los parámetros existentes en la época, e incluso dentro de un momento de grandes transformaciones como fue la Guerra Civil española. Las mujeres ocuparon aquellos cargos que se consideraban como "femeninos", limpiadoras, cocineras y mecanógrafas, fundamentalmente. Otro aspecto a destacar es que todas aquellas mujeres localizadas como miembros del Ateneo, tuvieron algún vínculo con algún miembro masculino de este centro, lo que pone el acento en el marcado carácter masculino del Ateneo. No obstante, se hace necesario dudar de las fuentes y del tipo de información que ofrecen, ya que a lo largo de la historia la actividad de las mujeres ha sido silenciada por aquellos que dejan vestigios del pasado. En este sentido, el que los expedientes de las mujeres hayan sido los menos densos 
documentalmente hablando, en comparación con los de sus compañeros, nos debería hacer reflexionar sobre el por qué. También el hecho de que se hayan encontrado 54 expedientes de hombres frente a 17 de mujeres.

Las mujeres que pertenecieron al Ateneo fueron acusadas, la mayoría de ellas, de vestir mono y llevar pistola, aspecto que fue reconocido por alguna de ellas, y lo cual es significativo, ya que nos indica que la mera vestimenta ya fue motivo de acusación por parte del régimen franquista. También cabría señalar como, salvo una excepción, las mujeres no fueron acusadas de cometer directamente los asesinatos sino de ser "instigadoras de los mismos", aspecto que no encontramos en el caso de los expedientes de los hombres. No obstante, las penas que recayeron sobre ellas no fueron inferiores que la de sus compañeros varones, a pesar de que las acusaciones contra ellas fueran menores. Sin embargo, este aspecto no ha sido abordado en profundidad debido a que no en todos los expedientes se establecía el tipo de condena a la que los y las acusados/as fueron condenados, y sobre todo, se hacía imposible su seguimiento en la cárcel, ya que las reducciones de pena o su conmutación aparecía en un número muy reducido de expedientes. Además de la gran ambigüedad presentada, donde a una persona acusada de "auxilio a la rebelión", le podían condenar a doce años y un día de reclusión mayor o menor, y a otra persona acusada de lo mismo a treinta años y un día de reclusión mayor o menor.

También habría que señalar las diferencias de edad entre las mujeres del Ateneo, teniendo la mayoría entre veinte y treinta años, aunque hubo mujeres entre los cuarenta y cincuenta años. El caso más significativo, el ya señalado de María González Saez, de la única que se establece que estuvo en el frente con dieciséis años. Este aspecto es significativo, ya que nos señala la mayor implicación de mujeres jóvenes en estos centros; un sector social, la juventud, donde las ideas de cambio y revolución estaban más presentes.

Otro de los aspectos que se ha podido constatar en este trabajo han sido las relaciones familiares y personales dentro del Ateneo. Como se puede apreciar en los cuadros referentes a las relaciones personales que se detallan a continuación, dentro del Ateneo existió un fuerte componente de relaciones intrafamiliares, que incidió en la organización dentro de este centro. Aquellas mujeres que fueron esposas, hermanas o que mantuvieron relaciones sentimentales con los hombres que dirigieron el Ateneo tuvieron un papel más destacado dentro del mismo. Un claro ejemplo, expuesto anteriormente, es el de José Luis Villaverde y su mujer María Luisa Abadía. José Luis Villaverde desempeñó un cargo relevante dentro del Ateneo, el de conserje. En los casos en los que él no se encontraba de servicio, esta función la asumió su mujer, ostentando así, de forma temporal, un cargo de responsabilidad y de poder frente al resto de socios y socias.

Cuadro 6. Relaciones personales. Padres e hijos en el Ateneo Libertario de Ventas

\begin{tabular}{|c|c|}
\hline Progenitores & Hijos/as \\
\hline Bonifacio Álvarez Ortiz & $\begin{array}{l}\text { Basilio Álvarez Agudo } \\
\text { Jerónimo Álvarez Agudo }\end{array}$ \\
\hline Maria Saez García & María González Saez \\
\hline Fermín Muñoz Tejada & $\begin{array}{l}\text { José Muñoz de la Fuente } \\
\text { Pilar Muñoz de la Fuente } \\
\text { Mercedes Muñoz de la Fuente }\end{array}$ \\
\hline José Nieto Botija & Baldomero Nieto Ramos \\
\hline
\end{tabular}

HISPANIA NOVA., 15 (2017), págs. 100-124 
S. GAHETE Y F. JIMÉNEZ, Relaciones personales y de poder en los centros libertarios madrileños. El caso del Ateneo Libertario de Ventas (verano-otoño de 1936)

Cuadro 7. Relaciones personales. Matrimonios en el Ateneo Libertario de Ventas

\begin{tabular}{|l|l|}
\hline \multicolumn{2}{|c|}{ Matrimonios } \\
\hline Maria Luisa Abadía & José Luis Villaverde Petralanda \\
\hline Martina Beodias Arcas & Felipe Reviso Mota \\
\hline Josefa Delgado Paredes & Gabriel Carmona Campillo \\
\hline Josefa Sánchez Jiménez & Antonio Salinas \\
\hline Fuente: Consejos de Guerra. AGHDM. Elaboración propia.
\end{tabular}

Cuadro 8. Relaciones personales. Relaciones extramatrimoniales en el Ateneo Libertario de Ventas

\begin{tabular}{|l|l|}
\hline \multicolumn{2}{|c|}{ Relaciones extramatrimoniales } \\
\hline Alejandro Blanco Velasco (casado) & Margarita \\
\hline Lucio Calvo Rodríguez (casado) & Pilar Bravo Montero \\
\hline Manuel Martínez Conesa & Pilar Bravo Montero \\
\hline Juan Carmona Campillo & Magdalena Dávila \\
\hline Julián Hernández & Magdalena López Salamanca \\
\hline José del Pozo & Gregoria Rubio Acosta \\
\hline Pablo Sorroca Tomás (sacristán) & Flora \\
\hline Fuente: Consejos de Guerra. AGHDM. Elaboración propia.
\end{tabular}

Cuadro 9. Relaciones personales. Hermanos/Hermanas en el Ateneo Libertario de Ventas

\begin{tabular}{|l|l|}
\hline \multicolumn{2}{|c|}{ Hermanos/Hermanas } \\
\hline Basilio Álvarez Agudo & Jerónimo Álvarez Agudo \\
\hline José Luis Villaverde Petralanda & Justo Villaverde Petralanda \\
\hline Gabriel Carmona Campillo & Juan Carmona Campillo \\
\hline Álvaro José Rossi García & Antonio Rossi García \\
\hline
\end{tabular}

Fuente: Consejos de Guerra. AGHDM. Elaboración propia. 
Cuadro 10. Relaciones personales. Cuñados/Cuñadas en el Ateneo Libertario de Ventas

\begin{tabular}{|l|l|}
\hline \multicolumn{2}{|c|}{ Cuñados/Cuñadas } \\
\hline María González Saez & Segundo Gamo \\
\hline José Morales Tinajero & José Rodríguez Moreno \\
\hline Fuente: Consejos de Guerra. AGHDM. Elaboración propia.
\end{tabular}

En los cuadros del uno al cinco, se pueden observar otras características de los componentes de este Ateneo Libertario de Ventas. Por un lado, se expone la edad de sus miembros, que se sitúa entre los veintiséis y los treinta y cinco años; correspondiendo el menor número a edades más avanzadas. En este sentido se puede destacar el carácter joven de sus miembros. En segundo lugar, en cuanto al sexo de sus componentes, ya se ha dicho con anterioridad como se ha localizado a un mayor número de hombres, 54, frente a las 17 mujeres localizadas. Destacamos, por tanto, el carácter masculino de este centro. En tercer lugar, el sector profesional al que pertenecieron, repartidos entre el sector secundario y el terciario siendo la profesión más repetida la de jornalero, dentro del sector primario. Este término ha de ser entendido de forma amplia, como persona que vende su fuerza de trabajo por un jornal, ya sea en el campo o, por ejemplo, en la construcción. Este tipo de trabajos, de carácter temporal, es un indicativo de la precariedad de algunos de los miembros del Ateneo Libertario de Ventas, y la necesidad de recurrir a formas sociales de solidaridad dentro de los miembros de sus círculos más cercanos dentro de la barriada para poder sacar a sus familias adelante. Sin embargo, al señalar la profesión en los expedientes judiciales, nos encontramos más que con la identificación laboral del detenido o detenida, con la interpretación y lectura de la condición socio-profesional del detenido/a por parte de las autoridades franquistas, por ello se pueden apreciar cambios en la profesión a lo largo de los diferentes interrogatorios del proceso judicial. Un claro ejemplo de esta práctica, estaría en los expedientes de las mujeres, ya que se las encuadró en "sus labores". Pero, como se ha señalado en el texto, las mujeres obreras trabajaban en sus domicilios o fuera de ellos, realizando labores de costura, lavado o trabajando en las fábricas. No obstante, un aspecto importante es la preponderancia del sector secundario y terciario, con 37 personas, frente a las 9 del apartado correspondiente al sector primario aunque los jornaleros bien podían ser inmersos dentro del sector secundario, dependiendo de la labor desempeñada. Todo ello es indicativo de la importancia de la industrialización de la económica madrileña y el progresivo abandono del mundo agrario. De hecho, Ventas fue uno de los límites geográficos del Madrid de los años 30, donde sus habitantes pudieron trabajar tanto en el mundo agrario como en la industria. Este fenómeno de industrialización requirió de trabajadores/as cualificados y formados, abriendo la posibilidad de la constitución de centros educativos alternativos a los estatales como los ateneos.

En cuarto lugar, destacaríamos la procedencia geográfica de los miembros del Ateneo, donde el mayor porcentaje, 20 de un total de 71, fueron de Madrid o de los pueblos cercanos. Fuera de Madrid, los principales focos de migración fueron Castilla la Nueva y Andalucía, cabría destacar, por tanto, el carácter rural de las personas inmigrantes. En quinto lugar, y para finalizar, subrayaremos la importancia del conocimiento de los cargos existentes en el Ateneo Libertario de Ventas, desarrollados

HISPANIA NOVA., 15 (2017), págs. 100-124 DOI: https://doi.org/10.20318/hn.2017.3482 
a lo largo de este trabajo, durante el conflicto, así como las personas que los desempeñaron. Ello nos permite conocer quiénes fueron los que tuvieron mayor poder y responsabilidad dentro del Ateneo, y las funciones realizadas por este centro.

Otro de los aspectos relevantes, dentro de este trabajo, ha sido el de analizar el prototipo de violento. Aunque hubo una mayor participación de los varones jóvenes en el proceso de detención y ejecución de aquellas personas consideradas enemigas por los miembros del Ateneo, esto no excluye a varones de otras edades o a las mujeres del proceso, es más, como se ha podido ver a lo largo del trabajo, hubo mujeres y hombres (estos últimos de todas las edades) que participaron activamente en el proceso de localización y ejecución de personas afines a los sublevados o sospechosas de serlo.

No se ha podido concretar tampoco el tiempo que el Ateneo estuvo en funcionamiento, aunque las fuentes dan a entender que se mantuvo abierto de forma ininterrumpida desde noviembre de 1933 hasta marzo de 1939. Sin embargo, sus funciones sí cambiaron durante todo este periodo. Por ejemplo, con la guerra apareció la función represiva, que, aunque no podemos concretar por cuánto tiempo se estuvo realizando, sí podemos afirmar que el periodo de mayor intensidad fue durante el verano-otoño de 1936.

En este artículo se han trabajado distintos aspectos sobre el Ateneo Libertario de Ventas que hasta ahora no habían sido abordados como: las relaciones de género dentro del mismo, su composición, los cargos o sus funciones sociales y culturales dentro de la barriada. No obstante, quedan todavía muchos más elementos que pueden ser analizados como: las diferentes actividades que se Ilevaron a cabo, las funciones represivas que asumió este centro tras el golpe de estado, su relación con el resto del anarquismo madrileño o con otros centros. También la relación entre los propios miembros del Ateneo, por ejemplo, si se conocieron en el centro de sociabilización anarquista del barrio, es decir, el Ateneo, o si la amistad procedía de la vecindad o de las relaciones laborales, Finalmente, otro de los aspectos que se puede estudiar es el proceso judicial que se llevó a cabo contra las personas que ocuparon el Ateneo, una vez acabada la guerra. 